\title{
GESTÃO DE PESSOAS NO SETOR PÚBLICO
}

Apesar da grande demanda por entender o que motiva e mobiliza os indivíduos encarregados da prestação de serviço público, ainda é pouco expressiva a pesquisa sobre gestão de pessoas no setor público no Brasil. Como objeto de estudos, caracteriza- se pelo ambiente institucional distinto do setor privado e pela natureza do trabalho, voltado à prestação de serviços à sociedade, e não ao lucro. Compreender os desafios da gestão de pessoas no setor público re- quer que se reconheçam as peculiaridades do ambiente institucional e organizacional da gestão, do perfil motivacional do servidor e das lideranças, dos processos de seleção, remuneração e engajamento, entre outros. Nesta seção, Fábio Klein (servidor público e doutor pela FGV-EAESP), a professora Mônica Pinhanez (FGV- EBAPE) e o professor André Ofenhejm Mascarenhas (Centro Universitário da FEl) sugerem livros clássicos e contemporâneos sobre o tema.

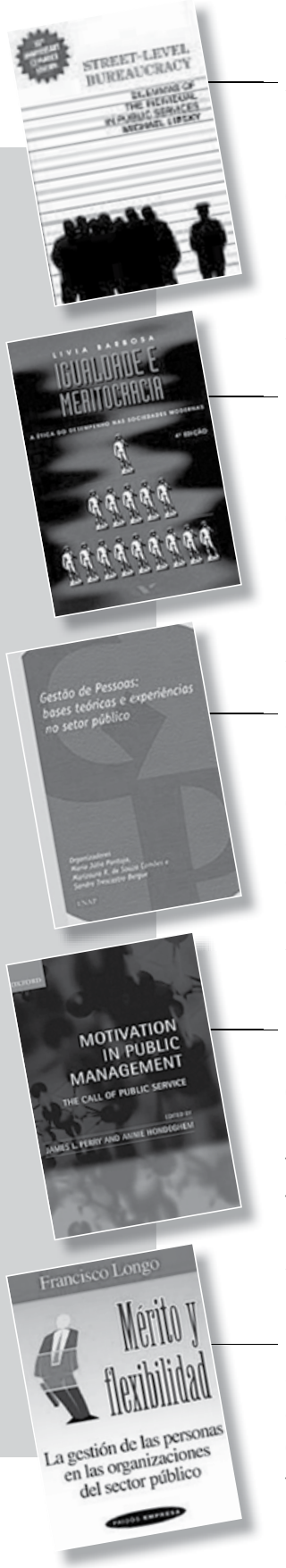

STREET-LEVEL BUREAUCRACY: The dilemmas of the individual in public services. Michael Lipsky. New York: Russell Sage Foundation, 2010. 275 p. A edição de 30 anos deste clássico reexamina como políticas públicas são traduzidas em práticas de trabalho por funcionários que lidam diretamente com o público (street-level bureaucrats). Mostra que 0 excesso e acúmulo de trabalho, os objetivos ambíguos das agências e a limitação de recursos afetam essas práticas, determinando a qualidade final dos serviços prestados aos cidadãos.

IGUALDADE E MERITOCRACIA: A ética do desempenho nas sociedades modernas. Lívia Barbosa. 4. ed. Rio de Janeiro: FGV, 2003. 216 p. Esta obra, referência no debate sobre a modernização do Estado brasileiro, faz uma análise cultural do conceito de "desempenho", contextualizando-o em termos do conjunto de significados que se constitui em um dos principais sistemas de hierarquização social nas sociedades modernas, a meritocracia. A análise comparativa entre Brasil, EUA e Japão revela as múltiplas formas e dilemas da implementação da meritocracia em sociedades distintas.

GESTÃO DE PESSOAS: Bases teóricas e experiências no setor público. Marizaura Reis de Souza Camões, Maria Júlia Pantoja e Sandro Trescastro Bergue (orgs.). Brasília: ENAP, 2010. 346 p. Este livro articula o pensamento acadêmico e a discussão prática sobre os desafios de gerir, motivar e mensurar o desempenho no setor público. Dentre os diversos temas discutidos, destacam-se a gestão estratégica, gestão de desempenho, aprendizado e desenvolvimento de competências, sistemas de avaliação e remuneração.

MOTIVATION IN PUBLIC MANAGEMENT: The call of public service. James Perry e Annie Hondeghem (Eds.). New York: Oxford University, 2008. 352 p. Este livro faz uma revisão sobre o que direciona 0 comportamento de funcionários do governo e empresas públicas. Baseado em 25 anos de debate, em contexto norte-americano, revela a fragmentação do conhecimento na área, suas lacunas e oportunidades de pesquisa futura, discute fundamentos teóricos e desafios metodológicos. Argumenta que a teoria motivacional deveria fundamentar-se, além das escolhas racionais, em perspectivas altruísticas e pró-sociais.

MÉRITO Y FLEXIBILIDAD: La gestión de las personas en las organizaciones del sector público. Francisco Longo. Barcelona: Paidos Iberica, 2004. 296 p. Esta obra vale-se da densidade acadêmica e experiência prática do autor para discutir o futuro da gestão de pessoas no setor público, analisar 0 impacto das ideologias do management e propor um modelo de gestão de pessoas com ênfase no mérito e flexibilidade. Apesar das características universais, é discutido em perspectiva comparada.

Fabio Alvim Klein faklein@yahoo.com n. Monica Pinhanez monica.pinhanez@fgv.br =. André Ofenhejm Mascarenhas andremascar@gmail.com 